\title{
Photon Mass
}

\section{Sergey Orlov \\ Petrozavodsk State University ion@sampo.ru}

\begin{abstract}
The atomic structure is presented on the basis of the theory of vortex gravitation. The feasibility and calculation of the values of the density and mass of electromagnetic particles are proposed. A calculation is made, which proves that the photon must have mass. In the calculations, some physical characteristics of electromagnetic particles that are accepted by modern physics are refuted.
\end{abstract}

Keywords: theory of vortex gravity, cosmology and cosmogony. Celestial mechanics.

\section{INTRODUCTION}

\section{Theory of Light}

The nature of light has been studied by scientists since the Renaissance. According to some scientists, light had a wave nature. Others defended the corpuscular theory of the origin of light. To the founders of the wave theory, in the first place, should be attributed Rene Descartes. He represented light as a disturbance in the world substance [1]. The founder of the corpuscular theory was Pierre Gassendi [2]. The same point of view was followed by Isaac Newton [3]. Later, the wave theory of light was investigated by Robert Hooke [4] and Christian Huygens [5]. Thomas Jung [6] in the early 19 th century, his experiments with diffraction received evidence for the recognition of the wave theory. In his opinion, different colors correspond to different wavelengths. In 1817 the wave theory of light was followed by Augustin Fresnel in 1817 [7]. When considering the problem of thermal equilibrium of an absolutely black body, Max Planck [8] formulated his idea of the emission of light by portions - light quanta, which were called photons. Experiments of Malus and Bio [9] with polarization provided, as it seemed then, convincing evidence in favor of corpuscular theory and against the wave theory. In quantum mechanics, the idea of Dui de Broglie [10] about corpuscular-wave dualism was confirmed.

In modern science, a photon is represented as a massless particle.

In this article, it is proposed to consider the nature of electromagnetic particles based on the author's «Theory of vortex gravity, cosmology and cosmogony» [11]. A photon is an extra small particle that has a mass. This mass can be determined according to the above theory.

The following section presents the basic principles of this theory.

\section{The Theory of Vortex Gravitation}

The theory of vortex gravity, cosmology and cosmogony is based on the assumption that gravity, all celestial bodies and elementary particles are created by etheric vortices (torsions). The values of the bodies (the system of bodies) and the corresponding vortices can vary by an infinite amount. The largest etheric vortex that a person can observe is the universal whirlwind, the smallest - the atomic whirlwind.

The orbital velocities of the ether in each vortex decrease in the direction from the center to the periphery, according to the inverse square law. The change in orbital velocities, in accordance with the Bernoulli principle, causes an inversely proportional change (increase) in the pressure in the ether. The pressure gradient creates 
the forces of vortex gravity and pushes the substance (body) into the zones with the least pressure, that is, in the center of the torsion bar. This pattern operates in the same way in ethereal vortices of any size.

The ether is an excessively little dense gas that permeates all bodies (substances), except for superdense ones. Therefore, the ether can only push these superdense bodies, which include nucleons and particles of electromagnetic radiation.

In the theory of vortex gravity [11], the Navier-Stokes equation for the motion of a viscous fluid (gas) was used to determine the pressure gradient in an ether vortex.

$$
\rho\left[\frac{\partial}{\partial \mathrm{t}}+\overrightarrow{\mathrm{v}} \cdot \operatorname{grad}\right] \overrightarrow{\mathrm{v}}=\overrightarrow{\mathrm{F}}-\operatorname{grad} \mathrm{P}+\eta \Delta \overrightarrow{\mathrm{v}}
$$

where - ether velocity vector, $\mathrm{P}$ - ether pressure, $\boldsymbol{\eta}$ - viscosity.

in cylindrical coordinates, taking into account the radial symmetry, $\mathrm{v}_{\mathrm{r}}=\mathrm{v}_{\mathrm{z}}=0, \mathrm{v}_{\phi}=\mathrm{v}(\mathrm{r}), \mathrm{P}=\mathrm{P}$ the equation can be written in the form of a system

$$
\left\{\begin{array}{l}
-\frac{\mathrm{v}(\mathrm{r})^{2}}{\mathrm{r}}=-\frac{1}{\rho} \frac{d \mathrm{P}}{d \mathrm{r}} \\
\eta \cdot\left(\frac{\partial^{2} \mathrm{v}(\mathrm{r})}{\partial \mathrm{r}^{2}}+\frac{\partial \mathrm{v}(\mathrm{r})}{\mathrm{r} \partial \mathrm{r}}-\frac{\mathrm{v}(\mathrm{r})}{\mathrm{r}^{2}}\right)=0
\end{array}\right.
$$

After the transformations, an equation is obtained for determining the gravitational forces in the ether vortex:

$$
\begin{aligned}
& \qquad \mathrm{F}=\mathrm{V} \times \rho \times \frac{\mathbf{v}_{\mathbf{e}}{ }^{2}}{\mathbf{r}} \quad(3), \\
& \text { with the following dependence } \mathrm{V}_{\mathbf{e}} \sim \frac{\mathbf{1}}{\sqrt{\mathrm{r}}} \text { where }
\end{aligned}
$$

$\mathrm{V}$ - the volume of nucleons in the body that is in the orbit of the torsion with a radius of - $\mathrm{r}$.

$\rho=8.85 \times 10^{-12}$ кг $/ \mathrm{M}^{3}$ - the density of the ether [12]

$\mathrm{V}_{\mathrm{e}}$ - the speed of the ether in the orbit $\mathrm{r}$

$\mathrm{r}$ - the radius of the considered orbit of the ether vortex

\section{Vortex Atomic Structure}

In the central part of any celestial, ethereal torsion, the centripetal acceleration of the ether reaches enormous values. Directly proportional to this acceleration corresponds to the pressure gradient in the ether or vortex gravity. Under the influence of a huge force of gravitation, the ether thickens and forms in the center of the torsion the super dense core of the celestial body. The density of the nucleus is so great that it can not be pierced by ether. Ether, with its rotation near the nucleus, touches its fixed surface. In these zones there is turbulence of the ether, the formation of vortices and atomic micro-torsions. These torsions create atoms, as well as the forces of atomic gravity. In the central part of the atomic torsion, according to the same scheme, the ether is condensed into a superdense state and a fixed nucleus of the atom is formed. In the zone of contact of the ether with the core, the same turbulence of the ether and the appearance of torsion corpuscles occur. The size of these torsions is many orders of magnitude smaller than the atomic torsion. In the torsion corpuscule, also, the ether is consolidated and the formation of particles. In these particles, the density of the substance also reaches a value that the ether can not permeate. Consequently, torsion corpuscles are transformed into material bodies that have masses. These bodies are various electromagnetic particles (electrons, photons or 
quarks, etc.). With increasing intrinsic mass, according to the law of conservation of the angular momentum of the rotation, electromagnetic particles inversely proportionally decrease their orbital velocity - from the velocity of the ether $\mathrm{v}_{\mathrm{e}}=$ to the speed of light $\mathrm{v}_{\mathrm{c}}=3 \times 10^{8} \mathrm{~m} / \mathrm{s}$.

The strength of the substance is provided by interatomic bonds. In the author's scientific work [13] it was determined that interatomic bonds are created only by vortex gravitation in an atomic torsion. Vortex gravity is created by the centripetal acceleration of the ether in this torsion. In [13], this acceleration was calculated on the surface of the atomic nucleus as:

$$
\frac{v_{e}^{2}}{r_{n}}=\frac{\left(7,4 \times 10^{17}\right)^{2}}{10^{-14}} \quad(4), \text { where }
$$

$\mathrm{V}_{\mathrm{e}=\mathrm{M}} / \mathrm{c}$ - ether velocity on the surface of the atomic nucleus

$\mathrm{r}=10^{-14} \mathrm{~m}$ - the radius of the nucleus

With this acceleration, on the basis of equation (3), the pressure gradient in the atomic, ether torsion creates a force of vortex gravity equal to:

$$
\mathrm{F}_{\mathrm{g}}=4,7 \times 10^{38} \times \mathrm{V}
$$

This force of atomic attraction corresponds to the known force of interatomic attraction of atoms and ensures the strength of the substance.

In the orbital circular circulation of electromagnetic particles around the nucleus of the atom, reactive centrifugal forces act on them, which are equal to:

$$
F_{C}=\frac{m \times v_{C}^{2}}{r}
$$

In a circular orbital motion, the reactive forces (6) should be equal to the forces of attraction (5), that is:

$$
\begin{aligned}
& \qquad F_{g}=F_{c}=\mathrm{V} \times \rho_{e} \times \frac{\mathbf{v}_{\mathbf{e}}^{2}}{\mathbf{r}}=\frac{m \times v_{c}^{2}}{r} \text { from where: } \\
& \frac{v_{e}^{2}}{v_{c}^{2}}=\frac{m}{V \times \rho}, \text { где } \frac{m}{V}=\rho_{\mathrm{h}} \text { - density of the corpuscle-photon or electron, then } \\
& \frac{\boldsymbol{v}_{\boldsymbol{e}}^{2}}{\boldsymbol{v}_{\boldsymbol{c}}^{2}}=\frac{\boldsymbol{\rho}_{\mathbf{h}}}{\boldsymbol{\rho}_{\boldsymbol{e}}}, \text { (7) }
\end{aligned}
$$

From the equation (7), we determine the density of the light photon-corpuscle- $\rho_{\mathrm{n},}$ taking into account the fact that the speed of the newly formed photon is equal to the speed of light $\mathrm{v}_{\mathrm{c}}=3 \times 10^{8} \mathrm{~m} / \mathrm{s}$. We transform equation (7) and determine the photon density $\rho_{n}$,

$$
\rho_{\mathrm{h}}=\frac{v_{e \times \rho_{e}}^{2}}{v_{c}^{2}}=\frac{\left(7,4 \times 10^{17}\right)^{2} \times 8.85 \times 10^{-12}}{\left(3 \times 10^{8}\right)^{2}}=5,4 \times 10^{7} \mathrm{~kg} / \mathrm{m}^{3}
$$

The calculated density of an electromagnetic particle has objective evidence of its existence under the condition that the interatomic attraction is created by the atomic vortex rotation of the ether.

To determine the mass of a photon, you need to know its volume. To do this, we will be guided by the research of Stephen Weinberg (14]. According to his statement, at least 20 billion $\left(2 \times 10^{10}\right)$ photons [14] per nucleon. 
The nucleon volume is equal to $\mathrm{Vn}=10^{-45} \mathrm{~m}^{3}$

Then the photon volume must be equal to

$$
\mathrm{V}_{\mathrm{h}}=\frac{10^{-45}}{2 \times 10^{10}}=0,5 \times 10^{-56} \mathrm{~m}^{3}
$$

And the photon mass will be:

$$
M_{h}=V_{h} \times \rho_{h}=0,5 \times 10^{-56} \times 5,4 \times 10^{7}=2,5 \times 10^{-49} \mathbf{~ k g}
$$

On the basis of equations 5 and 6 it follows that the photon can detach from the atom and move along a spiral, in accordance with the trajectory of Hohmann [15], for the following reasons:

1. Under the influence of its own gravity, the photon will be condensed more than the calculated values and then the centrifugal forces will exceed the gravitational ones.

2. The power of atomic gravity will decrease its value. In particular, this can be due to the heating of matter or atom. The pressure in the air at the center of the atomic torsion should thus increase, in accordance with the law of Charles [16]:

$$
\mathbf{T} \sim \mathbf{P}
$$

In this case, the pressure gradient should decrease, which will cause a decrease in the vortex atomic gravity. Then the centrifugal forces will prevail over the gravitational attraction.

\section{CONCLUSION}

In this paper, all calculations are made from the assumption that electromagnetic particles arise at the lowest orbit of the atomic torsion. It is possible that torsion corpuscles can appear on other orbits, or in atomic torsion, having other dynamic characteristics. In this case, the results presented can be subject to adjustment, but the physico-mathematical principle of calculations will correspond to this article.

The radius of an electron in modern physics is assumed to be $\mathrm{R}_{\mathrm{el}}=10^{-22} \mathrm{M}$ [17].

Consequently, the volume of an electron must be of the order of $10^{-66} \mathrm{~m}^{3}$. Its mass, with a higher calculated density in the order of $10^{8}$, should be equal to the order of $10^{-58} \mathrm{~kg}$.

The electron mass, in accordance with the fundamental constants, is assumed to be $10^{-39} \mathrm{~kg}$. Then, with an electron volume in the order of $10^{-66} \mathrm{~m}^{3}$, the electron density must be

$$
\rho_{\mathrm{el}}=\frac{m}{V}=\frac{10^{-39}}{10^{-66}}=10^{27} \mathrm{~m} / \mathrm{kg}
$$

With such a density, the orbital revolution of the electron along atomic orbits would be impossible. That is, on the basis of equation (5), the electron must be torn from the atom tangentially to the orbit much earlier than it will gain such a density. Consequently, the electron density should be slightly different from the above photon density.

As is known with increasing temperature of the conductor-metal, its electrical conductivity decreases. This phenomenon is explained by the decrease in the volume of the atomic torsion and its gravity, which causes instability of the electrons in their orbits. Such violations in the torsion coupling of electrons prevent the electrical conductivity of the heated metal. 


\section{REFERENCES}

1. The Treatise on Light Edited by Stephen Gaukroger, University of Sydney Publisher: Cambridge University Press https://doi.org/10.1017/CB09780511605727.005 pp 3-75

2. Pierre Gassendi. Fisher, Saul. 2009. Stanford Encyclopedia of Philosophy.

3. Isaac Newton. Smith, George. 2007. Stanford Encyclopedia of Philosophy.

4. Robert Hooke Source: Thomas Birch, The History of the Royal Society, vol. 3 (London: 1757), pp. 10-15.

5. C. Huygens (translated by Silvanus P. Thompson), Treatise on Light, London: Macmillan, 1912

6. "Young, Thomas (YN797T)". A Cambridge Alumni Database. University of Cambridge.

7. A. Fresnel, 1818, "Mémoire sur la diffraction de la lumière" (deposited 29 July 1818, crowned" 1819), in Fresnel, 1866-70, vol.1, pp.247-364; partly translated as "Fresnel's prize memoir on the diffraction of light", in Crew, 1900, pp.81-144. Not to be confused with the earlier memoir of the same title (Fresnel, 1816).

8. Planck M. Über das Gesetz der Energieverteilung in Normalspektrum // Ann. Physik. — 1901. — T. 4.

9. Kahr, Bart; Claborn, Kacey (2008), "The lives of Malus and his bicentennial law.", Chemphyschem : a European journal of chemical physics and physical chemistry (published Jan 11, 2008), 9 (1), pp. 43-58,

10. L. de Broglie: a) Some important papers: C.R.A.S., 177, p. 517, p. 548, p. 630, 1923; Philosophical Mag., XLVII, p. 446, 1924; J. Phys., série VI, t. VII, nº 11, p. 321, 1926; J. Phys., série VI, t. VIII, n 5, p. 225, 1927; J. Phys., 20, p. 963, 1959; C.R.A.S., 277, série B, p. 71, 1973; Found. of Phys. (with G. Lochak, J.A. Beswick and J. Vassalo Pereira), 6, p. 3, 1976. b) Books (among 44 titles): - Recherches sur la théorie des quanta (Thesis, 1924): first published in: Annales de Physique, 10e série, t. III, p. 22-128, 1925; german translation: Akademische Verlaggesellschaft, Leipzig, 1927; reprinted by Masson, Paris, 1963. - Selected papers on wave mechanics (with Léon Brillouin), Blackie \& Son, Glasgow, 1928. - Une tentative d'interpretation causale et non linéaire de la mécanique ondulatoire: la théorie de la double solution, Gauthier-Villars, Paris, 1956; english translation: Elsevier, Amsterdam, 1960. — La théorie de la mésure en mécanique ondulatoire (interprétation usuelle et interprétation causale), Gauthier-Villars, Paris, 1960. - Etude critique des bases de l-interprétation actuelle de la mécanique ondulatoire, Gauthier-Villars, Paris, 1963; english translation, Elsevier, Amsterdam, 1965. - La réinterprétation de la mécanique ondulatoire, Gauthier-Villars, Paris, 1971. - Contribution to: Foundations of quantum mechanics, Proc. Int. Schools Enrico Fermi, Varenna, 1971. — Les incertitudes d'Heisenberg et l'interprétation probabiliste de la mécanique ondulatoire, Gauthier-Villars, Paris, 1982 (with a long preface of G. Lochak on The evolution of the ideas of Louis de Broglie on the interpretation of wave-mechanics: translated in English in the Special issue of Found, of Physics devoted to Louis de Broglie, 1982.

11. S. Orlov. Foundation of vortex gravitation, cosmology and cosmogony. Global journal of science Frontier V A

12. V A Atsurovskiy. General ether-dynamics. Energoatomizdat. Moscow, Russia. 1990. Page 278.

13. Original Article J Phys Astr, Volume: 5( 3) http://www.tsijournals.com/articles/gravitational-propertiesof-atom-13432.html 
Photon Mass

14. The First Three Minutes: A Modern View of the Origin of the Universe (1977, updated with new afterword in 1993, ISBN 0-465-02437-8)

15. Walter Hohmann. Die Erreichbarkeit der Himmelskörper. — Verlag Oldenbourg in München, 1925. — ISBN 3-486-23106-5.

16. Castka, Joseph F.; Metcalfe, H. Clark; Davis, Raymond E.; Williams, John E. Modern Chemistry. — Holt, Rinehart and Winston, 2002. - ISBN 0-03-056537-5.

17. Dehmelt, Hans (1988). "A Single Atomic Particle Forever Floating at Rest in Free Space: New Value for Electron Radius". Physica Scripta T22: 102-110. DOI: 10.1088/0031-8949/1988/T22/016.

Citation: Sergey Orlov, "Photon Mass". American Research Journal of Computer Science and Information Technology, Vol 3, no. 1, 2018; pp:1-6.

Copyright (c) 2018 Sergey Orlov, This is an open access article distributed under the Creative Commons Attribution License, which permits unrestricted use, distribution, and reproduction in any medium, provided the original work is properly cited. 